\title{
Photocatalytic, Antimicrobial and Biocompatibility Features of Cotton Knit Coated with Fe-N-Doped Titanium Dioxide Nanoparticles
}

\author{
Miruna Silvia Stan ${ }^{1}$, Ionela Cristina Nica ${ }^{1}$, Anca Dinischiotu ${ }^{1, *}$, Elena Varzaru ${ }^{2}$, \\ Ovidiu George Iordache ${ }^{2}$, Iuliana Dumitrescu ${ }^{2, *}$, Marcela Popa ${ }^{3,4}$, \\ Mariana Carmen Chifiriuc ${ }^{3,4}$, Gratiela G. Pircalabioru 3,4, Veronica Lazar ${ }^{3,4}$, \\ Eugenia Bezirtzoglou ${ }^{5}$, Marcel Feder ${ }^{6}$ and Lucian Diamandescu ${ }^{6}$ \\ 1 Department of Biochemistry and Molecular Biology, Faculty of Biology, University of Bucharest, \\ 91-95 Splaiul Independentei, 050095 Bucharest, Romania; miruna.stan@bio.unibuc.ro (M.S.S.); \\ cristinai.nica@gmail.com (I.C.N.) \\ 2 National R\&D Institute for Textiles and Leather Bucharest (INCDTP), 16 Lucretiu Patrascanu, \\ 030508 Bucharest, Romania; elena.varzaru@certex.ro (E.V.); iordacheovidiu.g@certex.ro (O.G.I.) \\ 3 Department of Botanic-Microbiology, Faculty of Biology, University of Bucharest, 1-3 Aleea Portocalelor, \\ 60101 Bucharest, Romania; bmarcelica@yahoo.com (M.P.); carmen.chifiriuc@gmail.com (M.C.C.); \\ gratiela87@gmail.com (G.G.P.); lazar@botanic.unibuc.ro (V.L.) \\ 4 Research Institute of the University of Bucharest-ICUB, University of Bucharest, \\ 91-95 Splaiul Independentei, 050095 Bucharest, Romania \\ 5 Department of Agricultural Development, Democritus University of Thrace, 67100 Xanthi, Greece; \\ empezir@@agro.duth.gr \\ 6 National Institute of Materials Physics (NIMP), Atomistilor 405A, 077125 Bucharest-Magurele, Romania; \\ mfeder@infim.ro (M.F.); diamand@infim.ro (L.D.) \\ * Correspondence: anca.dinischiotu@bio.unibuc.ro (A.D.); iuliana.dumitrescu@certex.ro (I.D.); \\ Tel.: +40-21-318-1575 (A.D.); +40-21-340-4928 (I.D.)
}

Academic Editor: Carla Renata Arciola

Received: 1 August 2016; Accepted: 1 September 2016; Published: 21 September 2016

\begin{abstract}
Our research was focused on the evaluation of the photocatalytic and antimicrobial properties, as well as biocompatibility of cotton fabrics coated with fresh and reused dispersions of nanoscaled $\mathrm{TiO}_{2}-1 \% \mathrm{Fe}-\mathrm{N}$ particles prepared by the hydrothermal method and post-annealed at $400{ }^{\circ} \mathrm{C}$. The powders were characterized by X-ray diffraction (XRD), Mössbauer spectroscopy and X-ray photoelectron spectroscopy. The textiles coated with doped $\mathrm{TiO}_{2}$ were characterized by scanning electron microscopy and energy dispersive $X$-ray analyses, and their photocatalytic effect by trichromatic coordinates of the materials stained with methylene blue and coffee and exposed to UV, visible and solar light. The resulting doped $\mathrm{TiO}_{2}$ consists of a mixture of prevailing anatase phase and a small amount $(\sim 15 \%-20 \%)$ of brookite, containing $\mathrm{Fe}^{3+}$ and nitrogen. By reusing dispersions of $\mathrm{TiO}_{2}-1 \% \mathrm{Fe}-\mathrm{N}$, high amounts of photocatalysts were deposited on the fabrics, and the photocatalytic activity was improved, especially under visible light. The treated fabrics exhibited specific antimicrobial features, which were dependent on their composition, microbial strain and incubation time. The in vitro biocompatibility evaluation on CCD-1070Sk dermal fibroblasts confirmed the absence of cytotoxicity after short-term exposure. These results highlight the potential of $\mathrm{TiO}_{2}-1 \% \mathrm{Fe}-\mathrm{N}$ nanoparticles for further use in the development of innovative self-cleaning and antimicrobial photocatalytic cotton textiles. However, further studies are required in order to assess the long-term skin exposure effects and the possible particle release due to wearing.
\end{abstract}

Keywords: $\mathrm{TiO}_{2}-1 \%$ Fe-N; photocatalysis; textiles; antimicrobial properties; biocompatibility 


\section{Introduction}

The photodegradation of different environmental pollutants by photocatalysts, such as titanium dioxide $\left(\mathrm{TiO}_{2}\right)$, is one of the most studied processes. Between many advantages, such as mineralization of toxic and bio-resistant organic compounds [1-3], and the inactivation of pathogenic microorganisms [4], one of the main limitations of using $\mathrm{TiO}_{2}$ is the high quantity needed to obtain the desired effect.

Consequently, high amounts of waste are generated and released into the aquatic environment via effluents, where nanoparticles may pose an ecological risk $[5,6]$, while the photocatalyst recovery from the used dispersion is a very expensive process at the industrial scale [7]. One solution could be the multiple usage of the photocatalyst dispersion [8], even if the photo-catalytic activity decreases gradually $[9,10]$, due to the presence of adsorbed contaminants on its surface [11], or to the nanoparticles' agglomeration. Although many studies have been dedicated to the recovery or separation of $\mathrm{TiO}_{2}$ used for the treatment of contaminated waters [12-14] or to the regeneration of $\mathrm{TiO}_{2}$ immobilized on supports in the form of films [15], none of them were focused on the re-use of the $\mathrm{TiO}_{2}-1 \% \mathrm{Fe}-\mathrm{N}$ dispersion resulting from the textiles' treatment. By this approach, one could expect to reduce the amount of doped $\mathrm{TiO}_{2}$ released into the environment and, also, by using the same treatment bath, to decrease the consumption of water and chemicals.

It has been shown that the process of $\mathrm{TiO}_{2}$ doping with various metal or non-metal elements can extend or enhance their photoactivity under visible light, making it useful not only for the treatment of polluted water [16], but also for the development of antimicrobial agents and materials [17].

The nano $\mathrm{TiO}_{2}$-coated fabrics, as well as those impregnated with doped $\mathrm{TiO}_{2}$, can harbor significant antibacterial (against Escherichia coli and Staphylococcus aureus) and antifungal (against Candida albicans) [18] activity, as well as self-cleaning properties, while having no adverse effects on human dermal fibroblasts $[19,20]$.

In the current work, cotton fabrics were treated with $\mathrm{TiO}_{2}-1 \% \mathrm{Fe}-\mathrm{N}$ particles and with the dispersion remaining after the first treatment. The fabrics treated as described were characterized by scanning electron microscopy (SEM) and energy dispersive X-ray (EDX) analyses, while the modification of color parameters after staining with methylene blue (MB) and coffee was investigated after exposure to ultraviolet (UV) and visible light. In addition, the antimicrobial activity was evaluated against Gram-positive (S. aureus, Enterococcus faecalis, Bacillus subtilis) and Gram-negative (Pseudomonas aeruginosa, E. coli) bacterial reference strains using standardized quantitative assays of viable cell counts. Finally, biocompatibility was assessed by analyzing the cellular morphology, viability and cell membrane integrity of CCD-1070Sk normal human skin fibroblasts after $4 \mathrm{~h}$ of contact with the modified textiles in order to provide useful experimental data for further in vivo studies.

\section{Results}

\subsection{Photocatalyst Characterization}

\subsubsection{X-ray Diffraction Analysis}

The X-ray diffractograms of hydrothermally-synthesized Samples 1 and 2 are shown in Figure 1. In both cases, the XRD patterns consisted of two phases: a prevailing tetragonal anatase phase (ICSD \#9855) accompanied by the orthorhombic brookite (ICSD \#15409) phase. The Rietveld refinement results for both samples are presented in Table 1. The brookite amount obtained at pH 5.5 was a little bit higher than at $\mathrm{pH}$ 8.5. The crystallite size given by the Scherrer formula [21] belongs to the range of 8-12 nm. 


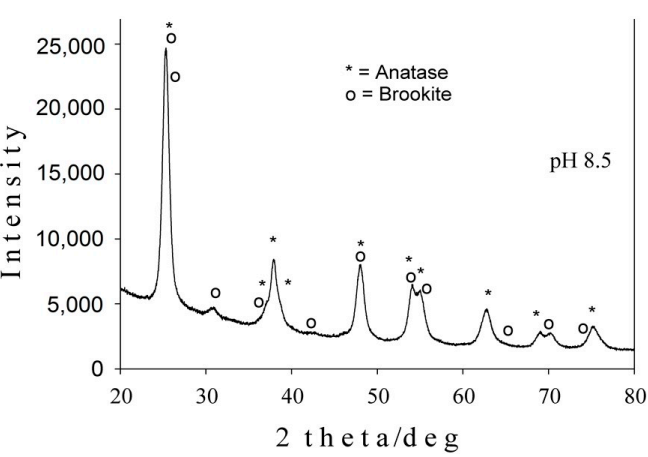

(a)

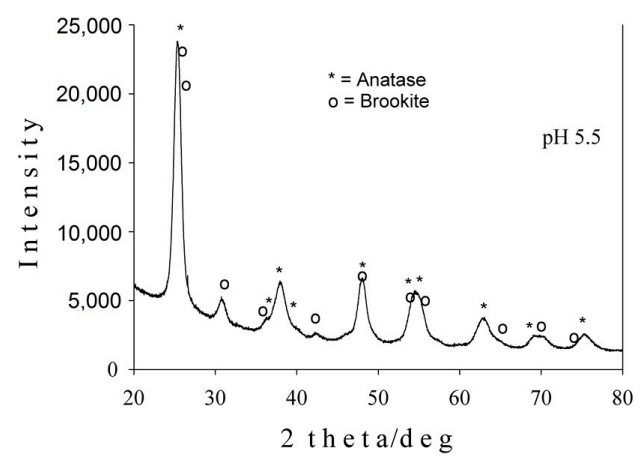

(b)

Figure 1. X-ray diffraction patterns of $\mathrm{TiO}_{2}-1 \%$ Fe-N samples obtained at $\mathrm{pH} 8.5$ (a) and pH 5.5 (b).

Table 1. Rietveld refinement parameters for $\mathrm{TiO}_{2}-1 \%$ Fe-N hydrothermal samples.

\begin{tabular}{|c|c|c|c|c|c|}
\hline \multirow{2}{*}{ Sample } & \multicolumn{3}{|c|}{ Lattice Parameters (̊̊) } & \multirow{2}{*}{$\begin{array}{l}\text { Crystallite Size } \\
(\mathrm{nm})\end{array}$} & \multirow{2}{*}{$\begin{array}{l}\text { Phase Assignment/Abundance } \\
\text { (wt \%) }\end{array}$} \\
\hline & $a$ & $b$ & $c$ & & \\
\hline Sample 1 & 3.7912 & - & 9.4909 & 12.3 & Anatase 85.3 \\
\hline$(\mathrm{pH}=8.5)$ & 9.1429 & 5.4215 & 5.2450 & 8.5 & Brookite 14.7 \\
\hline Sample 2 & 3.7907 & - & 9.4743 & 10.4 & Anatase 79.4 \\
\hline$(\mathrm{pH}=5.5)$ & 9.1629 & 5.4437 & 5.1809 & 11.6 & Brookite 20.6 \\
\hline Errors & \pm 0.0005 & \pm 0.0005 & \pm 0.0005 & \pm 1.5 & \pm 1.4 \\
\hline
\end{tabular}

\subsubsection{Mössbauer Spectroscopy}

The presence of iron in the obtained samples was evidenced by ${ }^{57} \mathrm{Fe}$ Mössbauer measurements at room temperature. The spectra (Figure 2) consisted of a central quadrupole pattern that was best deconvoluted into two doublets with Lorentzian lines. In good agreement with the XRD data, the most intense doublet corresponds to $\mathrm{Fe}^{3+}$ in the anatase phase (continuous red lines in Figure 2) and the less intense one to the brookite phase (blue lines in Figure 2). The characteristic Mössbauer hyperfine parameters isomer shift (IS), quadrupole splitting $\left(\Delta \mathrm{E}_{\mathrm{Q}}\right)$, line width $(\Gamma)$, together with the relative areas, as resulted from the fit with Lorentzian lines, are included in Table 2 . The obtained parameters are consistent with the presence of $\mathrm{Fe}^{3+}$ in both anatase and brookite structures.

The presence of nitrogen in the studied samples was evidenced by X-ray photoelectron spectroscopy (XPS) in our previous study [22]. A determination of the total nitrogen ratio detected by XPS related to the total $\mathrm{TiO}_{2}$ revealed the presence of 0.6 at $\% \mathrm{~N}$ in the studied samples.

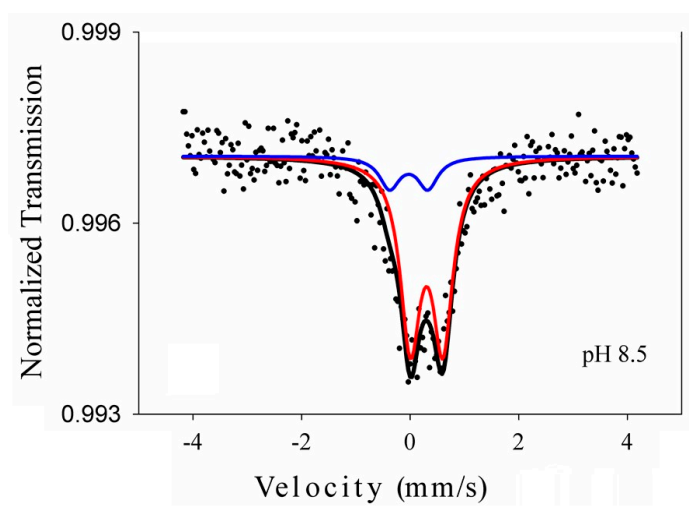

(a)

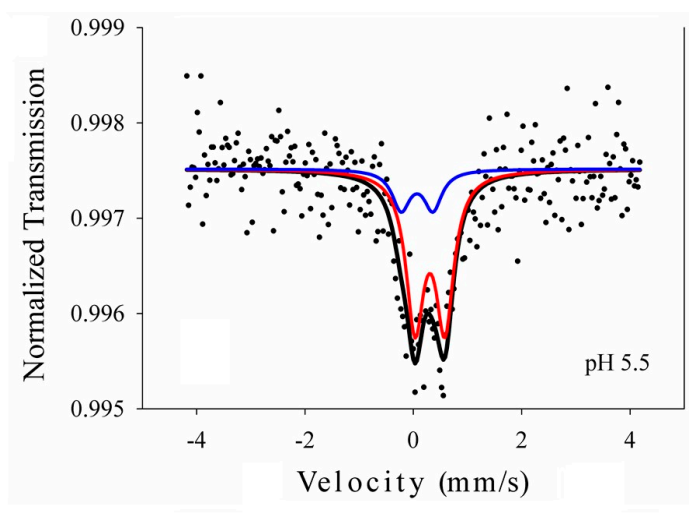

(b)

Figure 2. Mössbauer spectra of the hydrothermal samples at $\mathrm{pH} 8.5$ (a) and 5.5 (b) together with the computer fit (continuous lines). 
Table 2. Mössbauer fit parameters for the for $\mathrm{TiO}_{2}-1 \%$ Fe-N hydrothermal samples. IS, isomer shift.

\begin{tabular}{cccccc}
\hline Sample & IS $(\mathbf{m m} / \mathbf{s})$ & $\Delta \mathbf{E}_{\mathbf{Q}}(\mathbf{m m} / \mathbf{s})$ & $\boldsymbol{\Gamma}(\mathbf{m m} / \mathbf{s})$ & Areas $(\%)$ & Site/Phase Assignment \\
\hline \multirow{2}{*}{ Sample 1 } & 0.417 & 0.598 & 0.45 & 85.2 & $\mathrm{Fe}^{3+}:$ Anatase \\
& 0.096 & 0.703 & 0.46 & 14.8 & $\mathrm{Fe}^{3+}:$ Brookite \\
Sample 2 & 0.419 & 0.551 & 0.40 & 79.4 & $\mathrm{Fe}^{3+}:$ Anatase \\
Errors & 0.182 & 0.587 & 0.41 & 20.6 & $\mathrm{Fe}^{3+}:$ Brookite \\
\hline
\end{tabular}

\subsubsection{Photocatalytic Test}

The nanoscaled $\mathrm{TiO}_{2}-1 \% \mathrm{Fe}-\mathrm{N}$ samples prepared under hydrothermal conditions followed by post-annealing at $400{ }^{\circ} \mathrm{C} / 2 \mathrm{~h}$ were used to prepare thin films on quartz support. In a suspension containing the obtained nanopowders, polyethylene glycol (PEG 600) was added in order to ensure the best adherence of nanoparticles to the quartz surface. Before the photocatalytic test, the samples were calcined to remove PEG, then cleaned by exposure under a 30-W UV lamp $(\lambda=365 \mathrm{~nm})$ for $2 \mathrm{~h}$. After cleaning, the films were immersed for $2 \mathrm{~h}$ in methylene blue and finally dried at room temperature. The photocatalytic activity was measured by the intensity of pulsed light (visible $610 \mathrm{~nm}$ ) reflected from the sample surfaces coated with MB, over a period of $60 \mathrm{~min}$. In Figure 3, the absorbance (ABS), as given by the PCC-2 (ULVAC, Chigasaki, Kanagawa, Japan) tester in both visible and UV radiation, is shown for Samples 1 and 2. ABS is a measure of the MB degradation in time, as a result of the photocatalytic activity of $\mathrm{TiO}_{2}-1 \% \mathrm{Fe}-\mathrm{N}$ particles, under UV or visible light irradiation during measurements. The decomposition of MB under UV or visible light irradiation leads to a gradual decrease of optical absorption; thus, a higher negative ABS value means a better photocatalytic activity. A better activity in the visible spectrum in comparison with the UV light activity was noticed in the case of Sample $1(\mathrm{pH}=8.5)$. In contrast, the photocatalytic activity of Sample 2 was much lower than of Sample 1 in both the UV and visible regions, with a clear saturation tendency. The most probable key elements to explain the differences are the brookite content, which is higher in Sample 2, accompanied by surface peculiarities, absorbance properties and band gap energies.

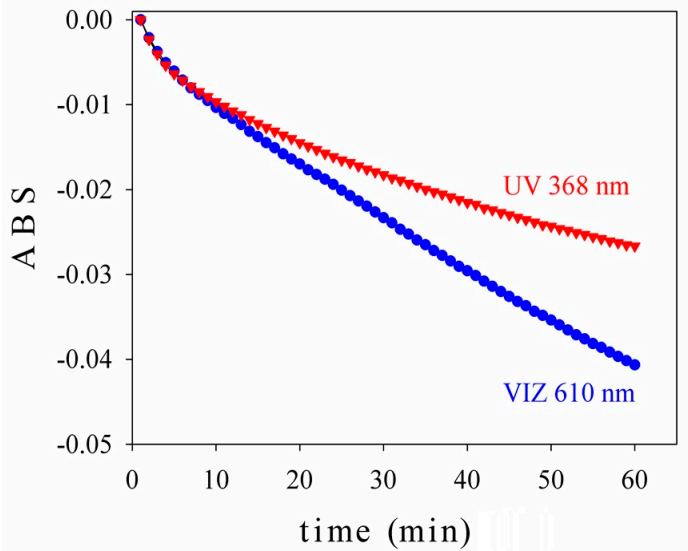

(a)

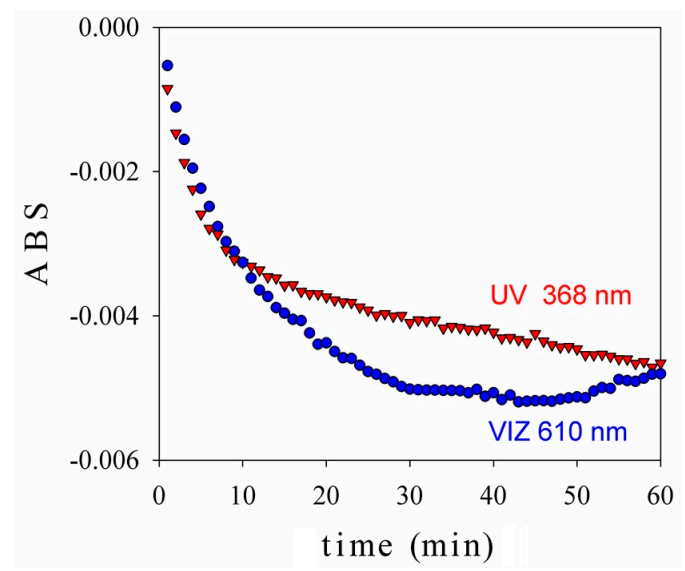

(b)

Figure 3. Photocatalytic degradation versus time of Sample 1 (a) and Sample 2 (b).

\subsection{Characterization of Treated Textile Materials by SEM-EDX}

Scanning electron microscopy analysis (SEM/EDX) of untreated and treated fabrics is presented in Figure 4 and Table 3. 


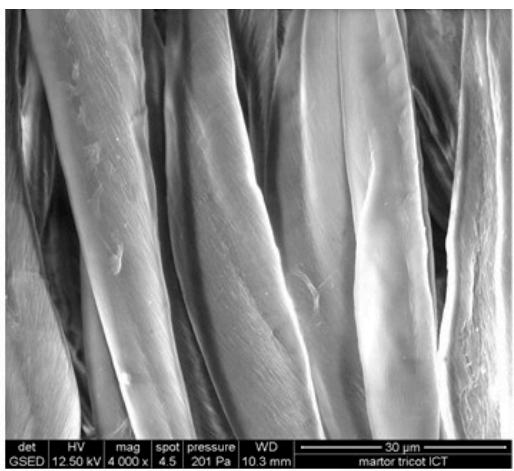

Control cotton knit

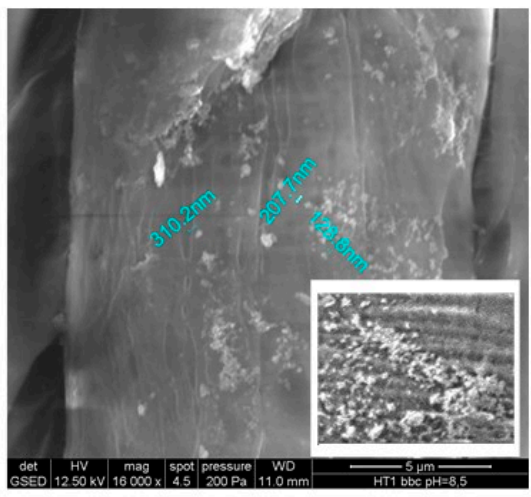

HT1 - knit treated with $\mathrm{TiO}_{2}-1 \% \mathrm{Fe}-\mathrm{N}$ (Sample 1)

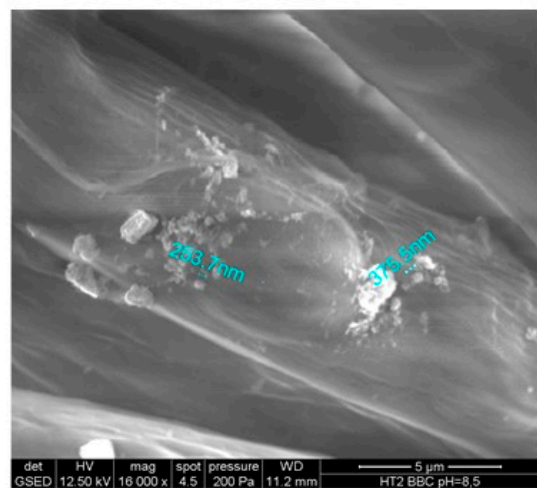

HT2 - knit treated with TiO2-1\% Fe-N (Sample 2)

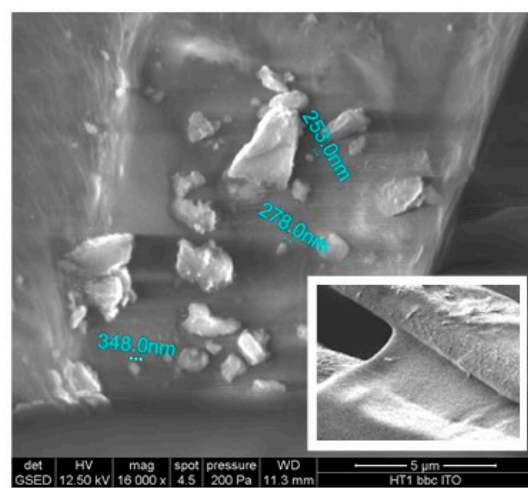

HT1 ITO-knit treated with $\mathrm{TiO}_{2}-1 \% \mathrm{Fe}-\mathrm{N}$ (Sample 1) and ITOBINDER AG

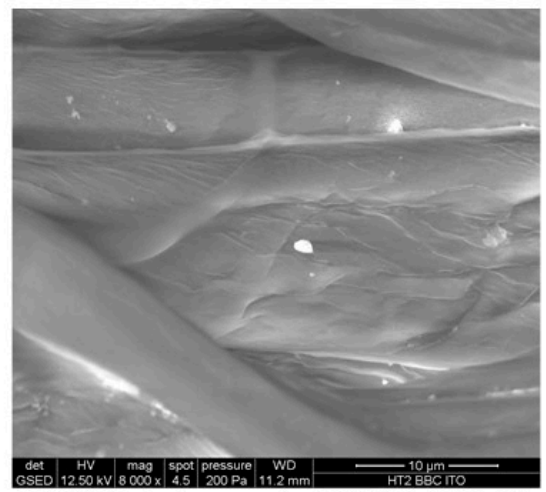

HT2 ITO - knit treated with TiO2-1\% Fe-N (Sample 2) and ITOBINDER AG

Figure 4. SEM analysis of untreated (control) and treated cotton fabrics.

The cotton knit treated with $\mathrm{TiO}_{2}-1 \%$ Fe-N Sample 1 (named HT1) was randomly covered with agglomerated particles, whose minimum sizes are 128.8, 207.7, $310.2 \mathrm{~nm}$. The treatment with Sample 2 (HT2-knit treated with $\mathrm{TiO}_{2}-1 \%$ Fe-N Sample 2) determined the deposition of a lower number of particles, more agglomerated, with higher dimensions (253.7, $375.5 \mathrm{~nm}$ ) in comparison with HT1.

On the fibers' surface treated with Sample 1 and acrylic binder ITOBINDER AG (HT1 ITO), the particles were rare and very large, due to the agglomeration caused by the polyacrylic binder. In the case of HT2 ITO (the knit treated with $\mathrm{TiO}_{2}-1 \%$ Fe-N sample 1 and ITOBINDER AG), the $\mathrm{TiO}_{2}-1 \%$ Fe-N particles could not be observed properly due to the acrylic polymer that coated the fibers in relatively thick layers. The percentage weights of Ti K are shown in the Table 3. 
Table 3. EDX analyses of the cotton knit treated with $\mathrm{TiO}_{2}-1 \% \mathrm{Fe}-\mathrm{N}$ (Samples 1 and 2) and polyacrylic binder.

\begin{tabular}{ccccc}
\hline Element, wt \% & HT1 & HT1 ITO & HT2 & HT2 ITO \\
\hline C K & 46.19 & 45.99 & 49.20 & 68.01 \\
O K & 43.71 & 34.93 & 45.77 & 29.44 \\
Ti K & $\mathbf{1 0 . 0 9}$ & $\mathbf{1 9 . 0 7}$ & $\mathbf{5 . 0 4}$ & $\mathbf{2 . 5 5}$ \\
Total & 100 & 100 & 100 & 100 \\
\hline
\end{tabular}

The amount of photocatalyst deposited on the materials was dependent on the characteristics of the dispersions and the photocatalysts used. Thus, the treatment of textiles by method P2, (represented by the immersion of the textile in the dispersion remained from the first treatment (named method P1) in which ITOBINDER AG was added to better fix the particles on the material's surface) with liquid that remained from the first treatment with $\mathrm{TiO}_{2}-1 \%$ Fe-N (Sample 1) has doubled the amounts of photocatalysts deposited, compared to those deposited by the first treatment (method P1). In the case of $\mathrm{TiO}_{2}-1 \%$ Fe-N (Sample 2), the treatment of textiles by method P2 slightly decreased the amounts deposited on cotton fabrics.

\subsection{Assessment of the Photocatalytic Effects of the Materials Treated with $\mathrm{TiO}_{2}-1 \% \mathrm{Fe}-\mathrm{N}$ Samples}

The color differences of the materials treated with photocatalysts, stained with methylene blue and exposed to light irradiation are shown in Tables 4 and 5. Positive values of the brightness difference $\left(\mathrm{dL}^{*}\right)$ demonstrated the color lightening of $100 \%$ cotton knit exposed to visible light, as compared to unexposed control samples. The most intensive discoloration after staining with MB was observed for the cotton knit treated with the dispersion remaining from the first impregnation with Sample 1 and acrylic binder (HT1 ITO) and on which surface the largest amount of $\mathrm{TiO}_{2}$ was deposited. The cotton fabric treated with the dispersion remaining from the first impregnation with Sample 2 and acrylic binder (HT2 ITO) has also shown a severe discoloration. The cotton knit treated with Sample 1 and stained with $\mathrm{MB}$ showed almost a triple discoloration $\left(\mathrm{dL}^{*}=5.48\right)$ comparing with those treated with Sample $2\left(\mathrm{dL}^{*}=2.07\right)$. In the case of cotton knit stained with coffee, a very slight discoloration was noticed.

Table 4. Trichromatic coordinates of the cotton knit treated with $\mathrm{TiO}_{2}-1 \% \mathrm{Fe}-\mathrm{N}$ (Samples 1 and 2), stained with $0.01 \mathrm{~g} / \mathrm{L}$ methylene blue (MB) and coffee exposed to visible light (Xenotest).

\begin{tabular}{|c|c|c|c|c|c|c|c|c|c|c|}
\hline Sample & $\mathbf{L}^{*}$ & $a^{*}$ & $\mathbf{b}^{*}$ & $\mathrm{dL}^{*}$ & $\mathrm{da}^{*}$ & $\mathrm{db}^{*}$ & $\mathrm{dE}^{*}$ & $\mathrm{dC}^{*}$ & $\mathrm{dH}^{*}$ & Grades \\
\hline $\begin{array}{l}\text { Control cotton knit } \\
\text { stained with } \mathrm{MB}\end{array}$ & 86.98 & -2.06 & -2.53 & 0.23 & 5.62 & 5.14 & 7.62 & -7.59 & 0.61 & 2 \\
\hline Cotton knit ITO-MB & 82.32 & -3.83 & -7.02 & 2.46 & 1.04 & 1.23 & 2.94 & -1.58 & 0.30 & 3.50 \\
\hline HT1-MB & 84.75 & -4.32 & -2.93 & 5.48 & 13.37 & 9.68 & 17.39 & -16.5 & -0.25 & 1 \\
\hline HT1 ITO-MB & 90.35 & -2.01 & -0.34 & 13.31 & 14.66 & 13.27 & 23.84 & -19.48 & -3.39 & 1 \\
\hline HT2-MB & 82.13 & -6.05 & -5.68 & 2.07 & 11.82 & 7.59 & 14.2 & -13.96 & 1.57 & 1 \\
\hline HT2 ITO-MB & 89.68 & -3.07 & -1.47 & 5.92 & 14.92 & 10.49 & 2.2 & -18.2 & -1.2 & 1 \\
\hline $\begin{array}{l}\text { Control cotton knit } \\
\text { stained with coffee }\end{array}$ & 80.26 & 4.96 & 19.72 & 3.46 & -0.68 & 0.45 & 3.56 & 0.26 & 0.77 & 3 \\
\hline $\begin{array}{l}\text { Cotton knit } \\
\text { ITO-coffee }\end{array}$ & 71.95 & 6.86 & 22.17 & 1.82 & -0.72 & -2.42 & 3.12 & -2.53 & -0.03 & 3.50 \\
\hline HT1-coffee & 78.38 & 5.2 & 21.92 & 5.06 & -0.91 & 0.6 & 5.18 & 22.18 & - & 2.5 \\
\hline HT1 ITO-coffee & 82.25 & 4.99 & 22.61 & 4.88 & -1.33 & 0.68 & 5.1 & 0.34 & 1.46 & 2.5 \\
\hline HT2-coffee & 81.29 & 5.25 & 23.69 & 4.05 & -1.16 & 0.6 & 4.25 & 0.3 & 1.27 & 2.5 \\
\hline HT2 ITO-coffee & 80.98 & 5.56 & 25.26 & 2.9 & -0.67 & 1.54 & 3.35 & 1.34 & 1.01 & 3 \\
\hline
\end{tabular}

Color difference $\left(\mathrm{dE}^{*}\right)$ and brightness $\left(\mathrm{dL}^{*}\right)$ were slightly higher than those of the non-exposed samples. The highest values were recorded on the knits treated with the remaining solution from the first impregnation with Sample 1 and acrylic binder (HT1 ITO) followed by HT1, regardless of the stain type. The polyacrylic binder delays the photodegradation of both coffee and MB. Between the untreated 
and treated material, there was a difference of $0.5-1$ grade on the gray scale, indicating a more rapid degradation of stains due to the applied treatments.

Table 5. Trichromatic coordinates of the cotton knit treated with $\mathrm{TiO}_{2}-1 \% \mathrm{Fe}-\mathrm{N}$ (Samples 1 and 2), stained with $0.01 \mathrm{~g} / \mathrm{L} \mathrm{MB}$ and coffee, exposed to UV light.

\begin{tabular}{ccccccccccc}
\hline Sample & $\mathbf{L}^{*}$ & $\mathbf{a}^{*}$ & $\mathbf{b}^{*}$ & $\mathbf{d L}^{*}$ & $\mathbf{d a}^{*}$ & $\mathbf{d b}^{*}$ & $\mathbf{d E}^{*}$ & $\mathbf{d C}^{*}$ & $\mathbf{d H}^{*}$ & $\mathbf{G r a d e s}$ \\
\hline Control cotton knit & 87.38 & -5.06 & -2.61 & 3.2 & 5.68 & 6.58 & 9.26 & -8.44 & -2.07 & 1.5 \\
stained with MB & & & & & & & & & & \\
Cotton knit ITO-MB & 77.67 & -18.76 & -15.15 & -2.36 & -0.61 & -0.19 & 2.44 & 0.59 & -0.24 & 3.50 \\
HT1-MB & 81.7 & -8.01 & -3.02 & 1.7 & 7.09 & 8.03 & 10.84 & -10.15 & -3.42 & 1.5 \\
HT1 ITO-MB & -8.47 & -1.55 & 2.12 & 9.41 & 11.52 & 15.03 & 14.46 & -13.54 & -6.17 & 1 \\
HT2-MB & 82.13 & -6.05 & -5.68 & 2.07 & 11.82 & 7.59 & 14.2 & -13.96 & 1.57 & 1 \\
HT2 ITO-MB & 87.76 & -7.04 & 2.31 & 2.93 & 7.46 & 10.02 & 12.83 & -9.02 & -8.65 & 1 \\
Control cotton knit & 73.19 & 5.96 & 21.56 & -5.72 & 1.71 & 5.22 & 7.93 & 5.49 & -0.29 & 2 \\
stained with coffee & & & & & & & & & \\
Cotton knit & 67.97 & 7.91 & 27.01 & 1.41 & -0.68 & -1.58 & 2.22 & -1.71 & 0.20 & 4.00 \\
ITO-coffee & 74.76 & 5.13 & 21.55 & 0.4 & -0.01 & 2.18 & 2.22 & 2.11 & 0.55 & 4 \\
HT1-coffee & 75.47 & 7.31 & 24.87 & 3.06 & -1.12 & -0.30 & 3.27 & -0.63 & 0.98 & 3 \\
HT1 ITO-coffee & 76.05 & 5.28 & 24.39 & 1.97 & -0.45 & 3.18 & 3.77 & 2.99 & 1.18 & 3 \\
HT2-coffee & 74.83 & 6.01 & 24.71 & 2.07 & -0.77 & 2.26 & 2.97 & 1.98 & 1.34 & 3.5 \\
HT2 ITO-coffee & & & & & & & & &
\end{tabular}

After UV irradiation, the cotton fabric treated with sample 1 (HT1 ITO) and stained with MB showed the most intense discoloration $\left(\mathrm{dL}^{*}=9.41\right)$, the largest color difference $\left(\mathrm{dE}^{*}=14.46\right)$ and the lowest grade on the scale gray (grade $=1$ ) followed by fabric treated with Sample 2 (HT2 ITO and HT2). The materials stained with coffee showed higher values than the untreated control material demonstrating a reduced photocatalytic activity.

Under natural sunlight, the only material that presented higher brightness values and color differences and lower grades on the gray scale when compared to the untreated cotton knit was the fabric treated with Sample 1 (HT1) and stained with MB (Table 6). It is important to mention that a greater amount of $\mathrm{TiO}_{2}$ was deposited on its surface compared to the same material treated with Sample 2. The positive values of $\mathrm{da}^{*}$ indicated the red shift of the samples color exposed to solar radiation, being more pronounced in the case of materials treated with photocatalysts. This shift, combined with positive $\mathrm{db}^{*}$ values, which indicate the sample yellowing, demonstrate the dye degradation.

Table 6. Trichromatic coordinates of the cotton knit treated with $\mathrm{TiO}_{2}-1 \% \mathrm{Fe}-\mathrm{N}$ (Samples 1 and 2), stained with $0.01 \mathrm{~g} / \mathrm{L} \mathrm{MB}$ and coffee and exposed to solar light.

\begin{tabular}{|c|c|c|c|c|c|c|c|c|c|c|}
\hline Sample & $\mathbf{L}^{*}$ & $a^{*}$ & $\mathbf{b}^{*}$ & $\mathrm{dL}^{*}$ & $\mathrm{da}^{*}$ & $\mathrm{db}^{*}$ & $\mathrm{dE}^{*}$ & $\mathrm{dC}^{*}$ & $\mathrm{dH}^{*}$ & Grades \\
\hline $\begin{array}{l}\text { Control cotton knit } \\
\text { stained with } \mathrm{MB}\end{array}$ & 85.7 & -3.41 & -4.67 & 4.85 & 5.59 & 4.58 & 8.71 & -7.13 & 1.21 & 1.5 \\
\hline Cotton knit ITO-MB & 78.79 & -10.54 & -11.62 & 0.08 & 9.36 & 4.93 & 10.58 & -10.20 & 2.83 & 1.50 \\
\hline HT1-MB & 88.5 & -1.68 & -2.87 & 5.93 & 11.48 & 7.19 & 14.79 & -13.24 & 2.86 & 1 \\
\hline HT2-MB & 85.36 & -3.02 & -2.4 & 1.58 & 7.77 & 6.53 & 10.27 & -10.15 & -0.14 & 1.5 \\
\hline $\begin{array}{l}\text { Control cotton knit } \\
\text { stained with coffee }\end{array}$ & 69.48 & 8.07 & 26.77 & 0.23 & -1.08 & -3.57 & -3.73 & 0.01 & 1.01 & 3.5 \\
\hline $\begin{array}{l}\text { Cotton knit } \\
\text { ITO-coffee }\end{array}$ & 68.44 & 7.21 & 24.32 & -1.43 & -0.64 & -3.35 & 3.70 & -3.40 & -0.32 & 3.00 \\
\hline HT1-coffee & 78.17 & 4.64 & 21.04 & 2.54 & -0.59 & 1.25 & 2.9 & 1.08 & 0.87 & 3.5 \\
\hline HT2-coffee & 80.26 & 3.71 & 17.58 & 5.8 & -2.16 & -3.38 & 7.05 & -3.8 & 1.29 & 2 \\
\hline
\end{tabular}

Comparing the $\mathrm{dL}^{*}$ values after samples' exposure at UV and visible light (Tables 4 and 5, respectively), it is obvious that the discoloration was more intense under visible light due to the $\mathrm{TiO}_{2}$ doping with nitrogen and iron, which extended the $\mathrm{TiO}_{2}$ absorption range. Except sample HT2 ITO, as the $\mathrm{TiO}_{2}$ amount deposited on materials increased, so was the photocatalytic efficiency enhanced under visible light. 


\subsection{Antimicrobial Activity}

In this study, we report for the first time the antimicrobial activity and biocompatibility of cotton textiles impregnated with $\mathrm{TiO}_{2}-1 \% \mathrm{Fe}-\mathrm{N}$, which were obtained by using the co-precipitation method at different $\mathrm{pH}$ values.

The tested materials exhibited specific antimicrobial features, depending on the tested microbial strain and the incubation time. All treated cotton knit materials inhibited the E. coli growth after $15 \mathrm{~min}$ of incubation. Statistically-significant results as compared to the untreated material have been obtained for HT1 $(p<0.01)$ and HT1 ITO $(p<0.001)$. Furthermore, the treated materials, except HT2 ITO, inhibited the P. aeruginosa growth, but significant differences compared to the untreated material have been noticed only for HT1 $(p<0.01)$. Excepting HT1 ITO, the treated materials inhibited the growth of the Gram-positive cocci strains, i.e., S. aureus and E. faecalis, with statistically significant results in the case of HT2 material against $S$. aureus $(p<0.001)$. HT1 and HT1 ITO inhibited the growth of B. subtilis after $15 \mathrm{~min}$ of incubation (Figure 5). Each of the tested materials inhibited preferentially the growth of a certain microbial strain, i.e., HT1 was the most efficient against P. aeruginosa, HT1 ITO against $E$. coli and $\mathrm{HT} 2$ against $S$. aureus.

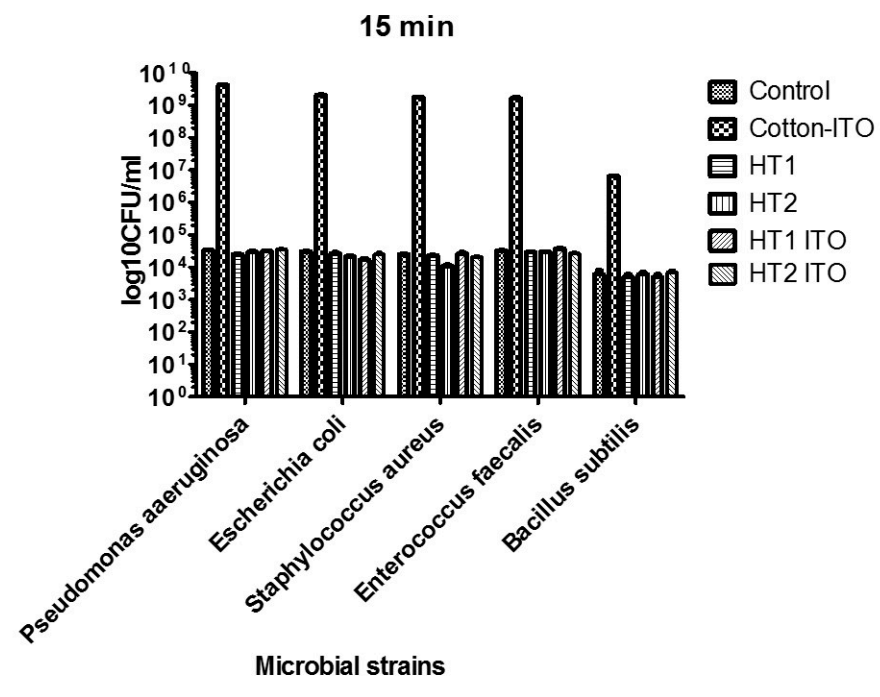

Figure 5. Graphic representation of the $\log _{10}$ colony forming units (CFU)/mL values of microbial biofilm cells grown on the cotton knit samples after 15 min of incubation.

The results were quantified only for three of the five tested bacterial strains, i.e., P. aeruginosa, E. coli and S. aureus, while for B. subtilis and E. faecalis, no microbial growth was obtained after $24 \mathrm{~h}$ of incubation, except for the untreated cotton samples containing only the acrylic binder.

For P. aeruginosa, the efficiency of the tested materials after $24 \mathrm{~h}$ was lower in comparison to that exhibited after $15 \mathrm{~min}$ of contact. The number of viable cells obtained in the presence of treated materials was similar to or even higher than that obtained on the control material (Figure 6). These results could be explained by the fact that the particles included in the tested material diffuse rapidly in the culture medium and exhibit a rapid bactericidal effect, decreasing the number of viable cells present in the initial bacterial suspension. However, after the consumption of the antimicrobial agent, the remaining viable $P$. aeruginosa cells start to multiply exponentially, reaching higher densities as compared to those of the initial inocula.

In the case of E. coli, the HT1 and HT2 ITO exhibited only a slight inhibitory effect (Figure 6). The HT2 samples, as well as both treated cotton knit containing the ITO acrylic binder, inhibited the growth of $S$. aureus at $24 \mathrm{~h}$. However, the differences registered in the number of viable cells that developed on the treated fabrics were not statistically significant $(p>0.05)$. 


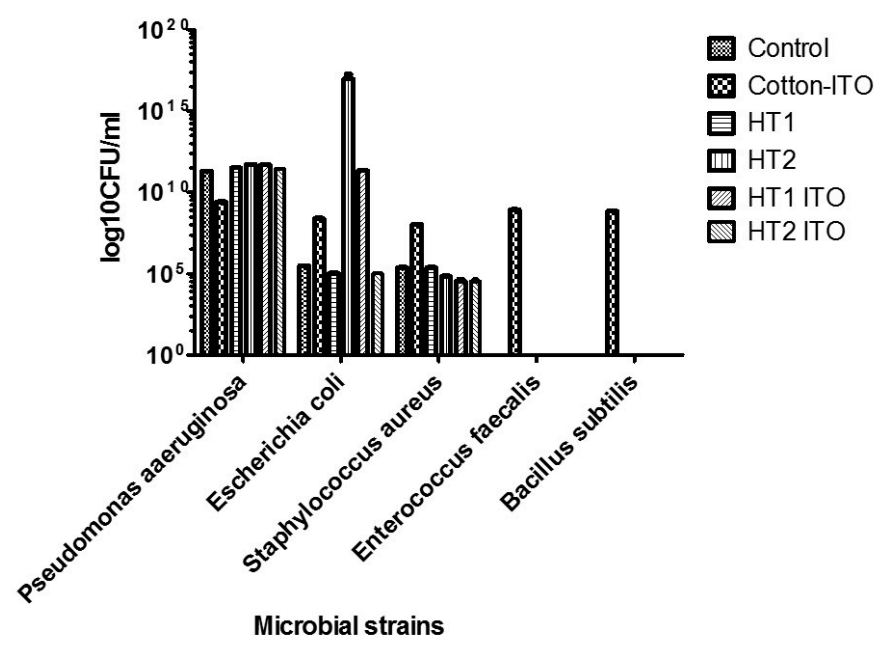

Figure 6. Graphic representation of the logarithmic values of $\mathrm{CFU} / \mathrm{mL}$ of viable cell counts recovered after $24 \mathrm{~h}$ of contact with the cotton knit samples.

These results could suggest that the addition of the polyacrylic binder, despite any intrinsic antimicrobial activity (as revealed by the high microbial load quantified on the untreated cotton samples containing ITO), could increase the antimicrobial activity of the treated materials by prolonging the inhibitory effect (Table 7).

Table 7. Representation of the material samples exhibiting antimicrobial activity against the tested microbial strains at different time intervals.

\begin{tabular}{cccc}
\hline \multicolumn{2}{c}{ Microbial Strain } & $\mathbf{1 5} \mathbf{~ m i n}$ & $\mathbf{2 4} \mathbf{h}$ \\
\hline \multirow{2}{*}{ Gram negative bacilli } & $\begin{array}{c}\text { P. aeruginosa } \\
\text { E. coli }\end{array}$ & HT1, HT2, HT1 ITO & - \\
& HT1, HT2, HT1 ITO, HT2 ITO & HT1, HT2 ITO \\
\hline Gram positive bacilli & B. subtilis & HT1, HT1 ITO & - \\
\hline \multirow{2}{*}{ Gram positive cocci } & S. aureus & HT1, HT2, HT2 ITO & HT2, HT1 ITO, HT2 ITO \\
& E. faecium & HT1, HT2, HT1 ITO & - \\
\hline
\end{tabular}

\subsection{Biocompatibility of Cotton Knit Treated with $\mathrm{TiO}_{2}-1 \%$ Fe-N Samples}

Taking into account that particles-treated textiles are intended to be marketed due to their self-cleaning and antibacterial properties, the biocompatibility of these materials is essential and should be rigorously assessed in order to check any possible risk of harmful effects that could be induced to the skin, such as cytotoxicity or inflammation. To fulfill this aim, the biocompatibility of $\mathrm{TiO}_{2}-1 \% \mathrm{Fe}-\mathrm{N}$-treated cotton knit was tested on normal human dermal fibroblasts, which were analyzed for viability, cell membrane integrity and inflammatory status (Figure 7). The period of incubation was selected at $4 \mathrm{~h}$, as this is considered the average time at which the toxic effects are visible on the skin during clothes wearing or after a contact with such functionalized fabrics.

The cell viability assessed by the 3-(4,5-dimethylthiazol-2-yl)-2,5-diphenyltetrazolium bromide (MTT) test was not significantly modified after exposure to $\mathrm{TiO}_{2}-1 \% \mathrm{Fe}-\mathrm{N}$, and only the HT1 ITO sample induced a slight increase of the optical density, suggesting that fibroblasts maintained their viability in the presence of particles-treated cotton knit. The level of lactate dehydrogenase (LDH) released in the culture medium during incubation with the treated samples remained near the value measured for the control material. Thus, no damage was induced to the cell membrane integrity after $4 \mathrm{~h}$ of direct contact with photocatalyst-treated materials. In addition, these data correlate with the level of NO released in the media, which did not change compared with the control, highlighting the 
lack of inflammation after $4 \mathrm{~h}$ of incubation. According to ISO 10993-5:2009 "Biological evaluation of medical devices-part 5: Tests for in vitro cytotoxicity" [23], these results indicate the biocompatibility of the treated samples meeting the criteria for further in vivo investigation for large-scale production on self-cleaning clothes market.

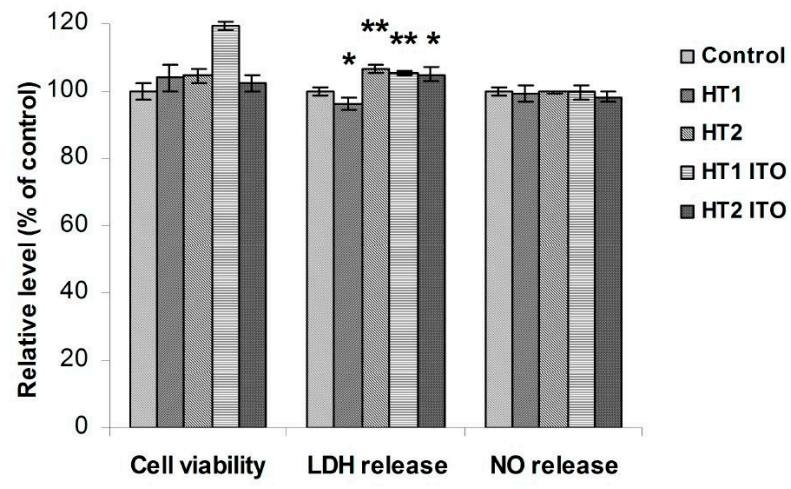

Figure 7. Biocompatibility of cotton knit treated with $\mathrm{TiO}_{2}-1 \% \mathrm{Fe}-\mathrm{N}$ samples after $4 \mathrm{~h}$ of incubation with dermal fibroblast cells as shown by cell viability, lactate dehydrogenase (LDH) release and NO level. Results are expressed as the mean $\pm \mathrm{SD}(n=3)$ and represented relative to the untreated cotton sample (control). ${ }^{*} p<0.05$ and ${ }^{* *} p<0.01$ compared to the control.

In order to assess the cell morphology during incubation with $\mathrm{TiO}_{2}-1 \%$ Fe-N-treated fabrics, the organization of the actin cytoskeleton was investigated by fluorescence microscopy (Figure 8). The human dermal fibroblast cell behavior was not significantly influenced in response to the photocatalyst-containing fabrics compared with the control, which is in accordance with the biocompatibility tests shown in Figure 7. The elongated flattened morphology and numerous focal adhesions between cells were maintained after $4 \mathrm{~h}$ of incubation with no significant differences between samples.
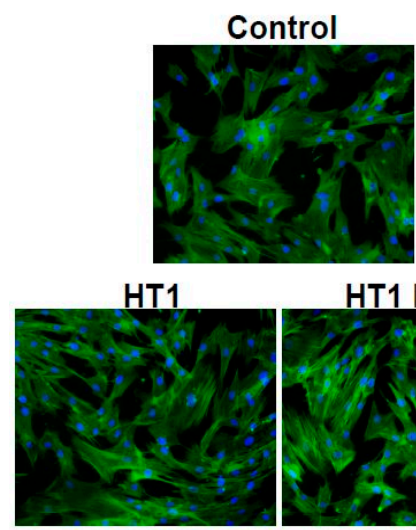

HT1 ITO

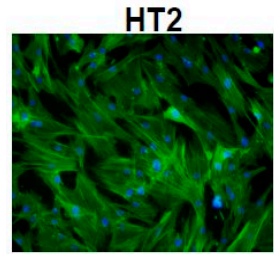

HT2 ITO

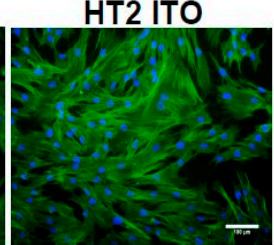

Figure 8. Actin cytoskeleton organization of dermal fibroblast cells after $4 \mathrm{~h}$ of incubation with cotton knit treated with $\mathrm{TiO}_{2}-1 \%$ Fe-N samples. F-actin (green) was labeled with phalloidin-fluorescein isothiocyanate (FITC), and nuclei (blue) were counterstained with 4',6-diamidino-2-phenylindole dihydrochloride (DAPI). Scale bar: $100 \mu \mathrm{m}$. 


\section{Discussion}

Iron- and nitrogen-doped nanoscaled titania $\left(\mathrm{TiO}_{2}-1 \% \mathrm{Fe}-\mathrm{N}\right)$ was synthesized under hydrothermal conditions at moderate temperature and pressure $\left(200{ }^{\circ} \mathrm{C}, 15 \times 10^{5} \mathrm{~Pa}\right)$. Samples obtained at $\mathrm{pH}$ values of 8.5 and 5.5 were further calcined at $400{ }^{\circ} \mathrm{C}$ for $2 \mathrm{~h}$. Both samples consisted of a mixture of nanoscaled $(8-12 \mathrm{~nm})$ anatase and brookite. Sample 1 , synthesized at $\mathrm{pH}=8.5$, exhibited the best photocatalytic activity under UV and visible irradiation.

Photocatalysts' dispersions remaining from the first treatment of textiles contain remarkable quantities of particles that can be re-used by treating the textile materials in the same bath. For better uptake and fixation of these particles, it is necessary to use a binder. The experimental results indicated that by reusing dispersions of $\mathrm{TiO}_{2}-1 \% \mathrm{Fe}-\mathrm{N}$, a high amount of photocatalysts was deposited on the fabric's surface, and the photocatalytic activity to decolorize methylene blue dye was improved. Comparing the results of irradiation with UV and visible light, we found that discoloration was more intense under visible light because of the $\mathrm{TiO}_{2}$ doping, which extended light absorption in the visible range. Applied on cotton fabrics, Sample 1 showed better photocatalytic efficiency under visible light when compared to Sample 2, while under UV rays; Sample 1 was less active than Sample 2, demonstrating the substrate importance for the photocatalytic activity.

The treated cotton knits exhibited specific antimicrobial features, depending on their composition, microbial strain and incubation time. The most susceptible microbial strain to the tested materials proved to be E. coli, followed by P. aeruginosa and the Gram-positive cocci strains. The most significant antimicrobial effect was observed after $15 \mathrm{~min}$ of incubation, the most effective materials being HT1 against $P$. aeruginosa, HT2 against $S$. aureus and E. coli and HT1 ITO against E. coli. Taking into account the implication of these strains in a wide range of infectious diseases, which can occur through direct or indirect contact contamination, the obtained results look promising for the further use of the obtained fabrics in the development of novel textiles with improved antimicrobial properties. In addition, the in vitro biocompatibility evaluation on dermal fibroblast cells confirmed the absence of cytotoxicity after short-term exposure, sustaining the possible use of these innovative cotton textiles after further studies on the long-term skin exposure effects and the possible particle release due to wearing.

\section{Materials and Methods}

\subsection{Synthesis of Photocatalysts}

Two samples of $\mathrm{TiO}_{2}$ doped with $1 \% \mathrm{Fe}$ atoms and nitrogen were used as photocatalysts, starting from easily-accessible materials $\left(\mathrm{TiCl}_{3}, \mathrm{FeCl}_{3}\right.$ and urea). For the synthesis of 1 at $\% \mathrm{Fe}-\mathrm{N}$ co-doped $\mathrm{TiO}_{2}$, the calculated amounts of $\mathrm{FeCl}_{3} \cdot 6 \mathrm{H}_{2} \mathrm{O}$ and $\mathrm{TiCl}_{3}$ were introduced under vigorous stirring in distilled water. The $\mathrm{pH}$ value was adjusted to 8.5 for Sample 1 and 5.5 for Sample 2 with $25 \% \mathrm{NH}_{4} \mathrm{OH}$ solution. The precipitate of $\mathrm{Ti}$ (III) hydroxide was oxidized at room temperature with oxygen (air) until the color changes from blue-violet to white. The co-precipitated form of Ti (IV) and Fe (III) hydroxides was washed with distilled water in order to remove salts and then dried in air at $105^{\circ} \mathrm{C}$. For the nitrogen doping, the as-resulted co-precipitate was hydrothermally treated at $200{ }^{\circ} \mathrm{C}$ for $2 \mathrm{~h}$ in the presence of urea, in a Teflon-lined autoclave. Finally, the dried powder was calcined at $400{ }^{\circ} \mathrm{C}$ for $2 \mathrm{~h}$ in air.

\subsection{Preparation of the Photocatalysts for Deposition on Textiles}

Amounts of $0.2 \mathrm{~g}$ photocatalyst powder and $0.006 \mathrm{~g}$ polyvinylpyrrolidone (PVP), respectively, were introduced in $400 \mathrm{~mL}$ of distilled water and stirred for $60 \mathrm{~min}$ in an ultrasonic bath. The final $\mathrm{pH}$ was adjusted to 8.5 with $1 \mathrm{~N} \mathrm{NaOH}$, which is relatively distant from pHpzc (point of zero charge) of $\mathrm{TiO}_{2}$, diminishing the repulsion forces between the particles and, consequently, their agglomeration. In addition, $\mathrm{NaOH}$ exhibits a swelling effect on textiles, especially on cotton, favoring the absorption of the photocatalysts. 
PVP was used in formulating photocatalysts' dispersions due to its ability to form molecular thin films on the surface of the particles, thereby preventing their agglomeration and sedimentation. Furthermore, PVP is a good moisturizer, absorbing over $40 \%$ of atmospheric moisture and, thus, contributing to the improvement of the photocatalytic effects.

\subsection{Cotton Knit Treatment}

\subsubsection{Method P1}

One hundred percent cotton $\mathrm{knit}\left(213 \mathrm{~g} / \mathrm{m}^{2}, 148 / 137.5\right.$ wales/courses; $1.08 \mathrm{~mm}$ thickness) was washed at $90{ }^{\circ} \mathrm{C}$ with water to remove any contaminants and detergent traces. The washed material was immersed in the above prepared photocatalyst dispersions, sonicated for $60 \mathrm{~min}$ at $40{ }^{\circ} \mathrm{C}$ and then dried in an oven at $100{ }^{\circ} \mathrm{C}$ for $60 \mathrm{~min}$. It is important to note that a large amount of particles remained in the dispersion after this first treatment.

\subsubsection{Method P2}

In order to increase the degree of exhaustion of the treatment bath and to reduce the amount of $\mathrm{TiO}_{2}$ particles introduced into wastewaters, new textile materials were immersed in the remaining dispersion and treated in similar conditions as above. To fix the particles, the wet materials were immersed in $20 \mathrm{~mL} / \mathrm{L}$ polyacrylic binder (ITOBINDER AG, self-cross linking aqueous acrylic copolymer emulsion acquired from LJ Specialities, Holmewood, UK, abbreviated ITO), maintained in an ultrasound bath for $30 \mathrm{~min}$ and then dried at $100^{\circ} \mathrm{C}$.

For comparisons, the fabric was treated with $400 \mathrm{~mL}$ solution containing $0.006 \mathrm{~g}$ PVP and $20 \mathrm{~mL} / \mathrm{L}$ ITO.

The treated materials were noted: cotton ITO, knit treated with PVP and ITO; HT1, knit treated with $\mathrm{TiO}_{2}-1 \%$ Fe-N (Sample 1); HT2, knit treated with $\mathrm{TiO}_{2}-1 \%$ Fe-N (Sample 2); HT1 ITO, knit treated with $\mathrm{TiO}_{2}-1 \%$ Fe-N (Sample 1) and ITO; HT2 ITO, knit treated with $\mathrm{TiO}_{2}-1 \%$ Fe-N (Sample 2) and ITO.

\subsection{Photocatalyst Characterization}

The crystallization of photocatalysts obtained under hydrothermal conditions followed by thermal annealing at $400{ }^{\circ} \mathrm{C}$ for $2 \mathrm{~h}$ was highlighted by X-ray diffraction (XRD). A Bruker D8 Advance diffractometer (Bruker, Hamburg, Germany) using $\mathrm{Cu}$ K $\alpha$ radiation $(\lambda=1.5406 \AA)$ was used. The presence of iron in the $\mathrm{TiO}_{2}$ lattice was revealed by room temperature ${ }^{57} \mathrm{Fe}$ Mössbauer transmission spectra recorded using a WissEL-ICE Oxford Mössbauer cryomagnetic system (Wissenschaftliche Elektronik GmbH, Starnberg, Germany, and ICE Innovative cryogenic system, Oxford, UK). The photocatalytic properties of Samples 1 and 2 (films on quartz) in the degradation of methylene blue, in both UV and visible regions, were investigated by means of the PCC2- ULVAC photocatalytic checker (ULVAC, Chigasaki, Kanagawa, Japan).

The morphology of the fabrics' surfaces treated with photocatalysts and the amount of deposited metals were analyzed by SEM (Quanta 200, FEI, Eindhoven, The Netherlands) equipped with an EDX detector. Assessment of the photocatalytic effects was performed by staining the blank materials and those treated with $\mathrm{TiO}_{2}-1 \% \mathrm{Fe}-\mathrm{N}$ (Sample 1 and Sample 2) with $0.01 \mathrm{~g} / \mathrm{L} \mathrm{MB}$ solution and coffee ( 3 coffee teaspoons in $500 \mathrm{~mL}$ water). The materials were half covered with paper and were exposed to UV light $(254 \mathrm{~nm})$ in a completely closed cabinet and to visible light in a laboratory equipment, Xenotest. Chromaticity coordinates of exposed and non-exposed materials were measured by an UltraScan PRO Hunterlab UV-Vis spectrophotometer (Hunter Associates Laboratory, Reston, VA, USA). The color differences between the treated samples and the blank were measured via the CIE L*a* ${ }^{*}$ scale specified by the "Commission Internationale de l'Éclairage" (CIE) [23], where:

- $\mathrm{L}^{*}$ represents lightness, $\mathrm{a}^{*}$ signifies the red/green value and $\mathrm{b}^{*}$ is the yellow/blue value;

- $\mathrm{dL}^{*}=\mathrm{L}^{*}$ sample $-\mathrm{L}^{*}$ control; if $\mathrm{dL}^{*}$ is positive, the sample is lighter than the control and, if $\mathrm{dL}^{*}$ is negative, the sample is darker than the control; 
- $\mathrm{da}^{*}=\mathrm{a}^{*}$ sample $-\mathrm{a}^{*}$ control; if $\mathrm{da}^{*}$ is positive, the sample is redder than the control. If $\mathrm{da}^{*}$ is negative, the sample is greener than the control;

- $\mathrm{db}^{*}=\mathrm{b}^{*}$ sample $-\mathrm{b}^{*}$ control; if $\mathrm{db}^{*}$ is positive, the sample is yellower than the control. If $\mathrm{db}^{*}$ is negative, the sample is bluer than the control;

- $\mathrm{dE}^{*}$ represents the total difference or distance on the CIELAB diagram as a single value for colour $\left(\mathrm{da}^{*}, \mathrm{db}^{*}\right)$ and lightness $\left(\mathrm{dL}^{*}\right)$ and, is calculated according to the following formula: $\mathrm{dE}^{*}=\sqrt{d L^{* 2}+d a^{* 2}+d b^{* 2}}$.

\subsection{Antimicrobial Activity Assay}

The Gram-positive S. aureus ATCC 6538, E. faecalis ATCC 29212 and B. subtilis ATCC 6633 and the Gram-negative P. aeruginosa ATCC 27853 and E. coli ATCC 8739 were purchased from American Type Culture Collection (ATCC, Virginia, USA). Glycerol stocks were streaked on LB agar to obtain 24-h cultures to be used for all further studies.

Monospecific biofilm development was assessed at two different times of exposure, i.e., $15 \mathrm{~min}$ and $24 \mathrm{~h}$. The textile materials were cut in equal circular samples of $8 \mathrm{~mm}$ and sterilized by autoclaving at $121{ }^{\circ} \mathrm{C}$ for $15 \mathrm{~min}$. The sterile samples were then immersed in $1 \mathrm{~mL}$ of microbial suspensions of $\sim 10^{7}$ colony forming units (CFU)/ $\mathrm{mL}$ performed in sterile saline and left in contact for $15 \mathrm{~min}$ and $24 \mathrm{~h}$, respectively. After this interval, microbial suspensions incubated with the tested samples were vortexed and further serially ten-fold diluted, and $10 \mu \mathrm{L}$ of each serial dilution were plated in triplicate on LB agar. After $24 \mathrm{~h}$ of incubation at $37^{\circ} \mathrm{C}$, viable cell counts were performed, and the number of $\mathrm{CFU} / \mathrm{mL}$ for each sample was established.

\subsection{In Vitro Biocompatibility Assessment}

CCD-1070Sk normal human skin fibroblasts (purchased from ATCC, Cat. No. CRL-2091) were cultured at low passage in complete Eagle's minimum essential medium (MEM; Gibco/Invitrogen, Carlsbad, CA, USA) containing 10\% fetal bovine serum (FBS; Gibco/Invitrogen) at $37{ }^{\circ} \mathrm{C}$ in a humidified atmosphere with $5 \% \mathrm{CO}_{2}$. Fibroblasts were grown to $70 \%-80 \%$ confluence within five to six days, then detached with $0.25 \%$ trypsin- $0.03 \%$ EDTA and transferred to new culture flasks. The cells were seeded at a density of $2 \times 10^{4}$ cells per square centimeter in a 24-well plate and were left to adhere overnight. Then, cotton samples cut into $1 \mathrm{~cm} \times 1 \mathrm{~cm}$, sterilized at $120^{\circ} \mathrm{C}$ for $20 \mathrm{~min}$ and exposed to a visible light source for $30 \mathrm{~min}$, were soaked in culture medium and placed over the attached fibroblasts without disturbing the cells, as was previously reported for other materials [24]. After $4 \mathrm{~h}$ of incubation, cytotoxicity tests were performed, and cell morphology and viability were evaluated. The untreated cotton sample (control) was used a control, and the results were expressed relative to this one.

The cell viability was measured using the 3-(4,5-dimethylthiazol-2-yl)-2,5-diphenyltetrazolium bromide (MTT; Sigma-Aldrich, St. Louis, MO, USA) assay (from the battery of cytotoxicity tests described in ISO 10993-5:2009, part 5) [25] which is based on the quantification of mitochondrial succinate dehydrogenase activity in the viable cells. Briefly, the culture medium and cotton samples were removed at the end of the exposure time, and cells were incubated with $1 \mathrm{mg} / \mathrm{mL}$ MTT for $3 \mathrm{~h}$ at $37{ }^{\circ} \mathrm{C}$ and $5 \% \mathrm{CO}_{2}$. The purple formazan crystals formed in the viable cells were dissolved with 2-propanol (Sigma-Aldrich, St. Louis, MO, USA), and the absorbance was measured at $595 \mathrm{~nm}$ using a microplate reader (GENiosTecan, Salzburg, Austria).

The LDH release was assessed as a measure of cell membrane integrity using a commercial kit (TOX7, Sigma-Aldrich, St. Louis, MO, USA) according to the manufacturer's instructions. Volumes of $50 \mu \mathrm{L}$ of culture supernatants were incubated with $100 \mu \mathrm{L}$ mix composed of equal parts of dye, substrate and cofactor for $30 \mathrm{~min}$. The reaction was stopped by adding $15 \mu \mathrm{L}$ of $1 \mathrm{~N} \mathrm{HCl}$, and the absorbance was read at $490 \mathrm{~nm}$ using a GENiosTecan microplate reader.

The level of nitric oxide (NO) released in the culture medium as an indicator of inflammation was determined using the Griess reagent. Culture supernatants were mixed with an equal volume 
of Griess reagent, a stoichiometric solution (v/v) of $0.1 \%$ naphthylethylenediamine dihydrochloride and $1 \%$ sulfanilamide in $5 \% \mathrm{H}_{3} \mathrm{PO}_{4}$. Absorbance was read at $550 \mathrm{~nm}$ using a GENiosTecan microplate reader, and the $\mathrm{NO}$ concentration was calculated on a $\mathrm{NaNO}_{2}$ standard curve.

Cell spreading and actin cytoskeleton morphology were investigated by fluorescence imaging using cells fixed with $4 \%$ paraformaldehyde for $20 \mathrm{~min}$ and permeabilized with $0.1 \%$ Triton X-100-2\% bovine serum albumin for $1 \mathrm{~h}$. Images were captured using an inverse fluorescence microscope Olympus IX71 (Olympus, Tokyo, Japan). Filamentous actin (F-actin) was labelled with $20 \mu \mathrm{g} / \mathrm{mL}$ phalloidin conjugated with fluorescein isothiocyanate (FITC) (Sigma-Aldrich, Munich, Germany), and nuclei were stained with $2 \mu \mathrm{g} / \mathrm{mL} \mathrm{4}$,6-diamidino-2-phenylindole dihydrochloride (DAPI) (Sigma-Aldrich, Munich, Germany).

\subsection{Statistical Analysis}

The antimicrobial activity and cell culture assays were performed in triplicate, and data were presented as the mean \pm standard deviation (SD). The statistical significance was analyzed by Student's $t$-test or two-way analysis of variance (ANOVA) followed by the Bonferroni post hoc test using GraphPad Prism 5, and a value of $p<0.05$ was considered significant.

Acknowledgments: The authors thank The Executive Unit for Financing Higher Education, Research, Development and Innovation (UEFISCDI) for the support in the frame of Partnership PN II project No. 87/2014 CLEANTEX (Innovative antibacterial and selfcleaning photocatalytic textiles). The authors Lucian Diamandescu and Marcel Feder thank the European Union and Romanian Government for the support allowing the acquisition of the research infrastructure under the Sectorial Operational Program "Increasing of Economic Competitiveness" (POS-CCE) project CEUREMAVSU (The Euro-Regional Center for the Study of Advanced Materials, Surfaces and Interfaces)-No. 01/01.03.2009.

Author Contributions: Miruna Silvia Stan performed the biochemical experiments, analyzed the data and drafted the manuscript. Ionela Cristina Nica, Elena Varzaru, Ovidiu George Iordache, Marcela Popa, Gratiela G. Pircalabioru, Marcel Feder and Lucian Diamandescu performed the experiments. Anca Dinischiotu, Iuliana Dumitrescu, Mariana Carmen Chifiriuc, Veronica Lazar, Eugenia Bezirtzoglou and Lucian Diamandescu conceived and designed the study and wrote the manuscript.

Conflicts of Interest: The authors declare no conflict of interest.

\section{References}

1. Ahmed, S.; Rasul, M.G.; Brown, R.; Hashib, M.A. Influence of parameters on the heterogeneous photocatalytic degradation of pesticides and phenolic contaminants in wastewater: A short review. J. Environ. Manag. 2010, 92, 311-330. [CrossRef] [PubMed]

2. Abid, M.F.; Abdulrahman, A.A.; Hamza, N.H. Hydrodynamic and kinetic study of a hybrid detoxification process with zero liquid discharge system in an industrial wastewater treatment. J. Environ. Health Sci. Eng. 2014, 12, 145. [CrossRef] [PubMed]

3. Ong, S.T.; Cheong, W.S.; Hung, Y.T. Photodegradation of commercial dye, methylene blue using immobilized $\mathrm{TiO}_{2}$. IPCBEE 2012, 43, 109-113.

4. Kozlova, E.A.; Safatov, A.S.; Kiselev, S.A.; Marchenko, V.Y.; Sergeev, A.A.; Skarnovich, M.O.; Emelyanova, E.K.; Smetannikova, M.A.; Buryak, G.A.; Vorontsov, A.V. Inactivation and mineralization of aerosol deposited model pathogenic microorganisms over $\mathrm{TiO}_{2}$ and $\mathrm{Pt} / \mathrm{TiO}_{2}$. Environ. Sci. Technol. 2010, 44, 5121-5126. [CrossRef] [PubMed]

5. Westerhoff, P.; Song, G.; Hristovski, K.; Kiser, M.A. Occurrence and removal of titanium at full scale wastewater treatment plants: Implications for $\mathrm{TiO}_{2}$ nanomaterials. J. Environ. Monit. 2011, 13, 1195-1203. [CrossRef] [PubMed]

6. Kiser, M.A.; Westerhoff, P.; Benn, T.; Wang, Y.; Pérez-Rivera, J.; Hristovski, K. Titanium nanomaterial removal and release from wastewater treatment plants. Environ. Sci. Technol. 2009, 43, 6757-6763. [CrossRef] [PubMed]

7. Fernández-Ibáñez, P.; Blanco, J.; Malato, S.; de las Nieves, F.J. Application of the colloidal stability of $\mathrm{TiO}_{2}$ particles for recovery and reuse in solar photocatalysis. Water Res. 2003, 37, 3180-3188. [CrossRef] 
8. Patel, J.R.; Patel, M.H.; Shrivastav, P.S.; Sanyal, M. Synthesis and dyeing behavior of two remazol reactive dyes with sulfo vinyl sulfone functionality on cotton fabric and their degradation study. J. Phys. Chem. Sci. 2014, 1, 1-6.

9. Jiang, P.; Ren, D.B.; He, D.; Fu, W.; Wang, J.; Gu, M. An easily sedimentable and effective $\mathrm{TiO}_{2}$ photocatalyst for removal of dyes in water. Sep. Purif. Technol. 2014, 122, 128-132. [CrossRef]

10. Lee, S.Y.; Park, S.J. TiO 2 photocatalyst for water treatment applications. J. Ind. Eng. Chem. 2013, 19, 1761-1769. [CrossRef]

11. Patel Jigar, R.; Patel Mitesh, H.; ShrivastavPranav, S.; Sanyal, M. Synthesis of a modified reactive dye with improved dyeing performance on cotton fabric and its degradation study. Indian J. Sci. 2013, 3, 45-51.

12. Malato, S.; Fernández-Ibáñez, P.; Maldonado, M.I.; Blanco, J.; Gernjak, W. Decontamination and disinfection of water by solar photocatalysis: Recent overview and trends. Catal. Today 2009, 147, 1-59. [CrossRef]

13. Nahar, M.S.; Hasegawa, K.; Kagaya, S. Photocatalytic degradation of phenol by visible light-responsive iron-doped $\mathrm{TiO}_{2}$ and spontaneous sedimentation of the $\mathrm{TiO}_{2}$ particles. Chemosphere 2006, 65, 1976-1982. [CrossRef] [PubMed]

14. Santos, J.M.; Valente, J.P.S.; Jorge, S.M.A.; Padilha, P.M.; Saeki, M.J.; Castro, G.R.; Florentino, A.O. Coagulation-flocculation of $\mathrm{TiO}_{2}$ in suspension used in heterogeneous photocatalysis. Orbital Electron. J. Chem. 2013, 5, 233-241.

15. Balasubramanian, G.; Dionysiou, D.D.; Suidan, M.T.; Baudin, I.; Laîné, J.M. Evaluating the activities of immobilized $\mathrm{TiO}_{2}$ powder films for the photocatalytic degradation of organic contaminants in water. Appl. Catal. B Environ. 2004, 47, 73-84. [CrossRef]

16. Fan, J.W.; Liu, J.Y.; Hong, J.; Zhang, J. The synthesis of nanostructure $\mathrm{TiO}_{2}$ co-doped with $\mathrm{N}$ and Fe and their application for micro-polluted source water treatment. Environ. Technol. 2009, 30, 1447-1452. [CrossRef] [PubMed]

17. He, R.L.; Wei, Y.; Cao, W.B. Preparation of (Fe, N)-doped $\mathrm{TiO}_{2}$ powders and their antibacterial activities under visible light irradiation. J. Nanosci. Nanotechnol. 2009, 9, 1094-1097. [CrossRef] [PubMed]

18. Dumitrescu, I.; Iordache, O.; Popescu, A.; Varzaru, E.; Kim, S.; Basim, B.; Ükelge, G. The photocatalytic effects of textiles treated with $\mathrm{TiO}_{2}$ and $\mathrm{Fe} / \mathrm{TiO}_{2}$. Ind. Text. 2015, 66, 297-305.

19. Behzadnia, A.; Montazer, M.; Rashidi, A.; Rad, M.M. Sonosynthesis of nano $\mathrm{TiO}_{2}$ on wool using titanium isopropoxide or butoxide in acidic media producing multifunctional fabric. Ultrason. Sonochem. 2014, 21, 1815-1826. [CrossRef] [PubMed]

20. Behzadnia, A.; Montazer, M.; Rashidi, A.; Rad, M.M. Rapid sonosynthesis of N-doped nano $\mathrm{TiO}_{2}$ on wool fabric at low temperature: Introducing self-cleaning, hydrophilicity, antibacterial/antifungal properties with low alkali solubility, yellowness and cytotoxicity. Photochem. Photobiol. 2014, 90, 1224-1233. [CrossRef] [PubMed]

21. Klug, H.P.; Alexander, L.E. X-ray Diffraction Procedures for Polycrystalline and Amorphous Materials; Wiley: New York, NY, USA, 1966; p. 491.

22. Diamandescu, L.; Feder, M.; Vasiliu, F.; Tanase, L.; Teodorescu, C.M.; Popescu, T.; Dumitrescu, I. Hydrothermal route to $(\mathrm{Fe}, \mathrm{N})$ codoped titania photocatalysts with increased visible light activity. Ind. Text. 2016, in press.

23. International Organization for Standardization. Joint ISO/CIE Standard: Colorimetry—Part 4: CIE 1976 L*$^{*} b^{*}$ Colour Space; ISO 11664-4:2008(E)/CIE S 014-4/E:2007; ISO: Geneva, Switzerland, 2007.

24. Prabhakar, P.K.; Raj, S.; Anuradha, P.R.; Sawant, S.N.; Doble, M. Biocompatibility studies on polyaniline and polyaniline-silver nanoparticle coated polyurethane composite. Colloids Surf. B Biointerfaces 2011, 86, 146-153. [CrossRef] [PubMed]

25. International Organization for Standardization. Biological Evaluation of Medical Devices_Part 5: Tests for in Vitro Cytotoxicity; ISO 10993-5:2009; ISO: Geneva, Switzerland, 2009.

(C) 2016 by the authors; licensee MDPI, Basel, Switzerland. This article is an open access article distributed under the terms and conditions of the Creative Commons Attribution (CC-BY) license (http://creativecommons.org/licenses/by/4.0/). 